\title{
Development of Robust Guaranteed Cost Mixed Control System for Active Suspension of In-Wheel-Drive Electric Vehicles
}

\author{
Xianjian Jin $\left(D,{ }^{1,2}\right.$ Jiadong Wang, ${ }^{2}$ and Junpeng Yang ${ }^{2}$ \\ ${ }^{1}$ School of Mechatronic Engineering and Automation, Shanghai Key Laboratory of Intelligent Manufacturing and Robotics, \\ Shanghai University, Shanghai 200072, China \\ ${ }^{2}$ State Key Laboratory of Automotive Simulation and Control, Jilin University, Changchun 130025, China
}

Correspondence should be addressed to Xianjian Jin; xianjianjin@shu.edu.cn

Received 8 May 2021; Revised 21 November 2021; Accepted 11 January 2022; Published 22 February 2022

Academic Editor: Jean Jacques Loiseau

Copyright (c) 2022 Xianjian Jin et al. This is an open access article distributed under the Creative Commons Attribution License, which permits unrestricted use, distribution, and reproduction in any medium, provided the original work is properly cited.

\begin{abstract}
This paper presents a mixed $\mathrm{H}_{2} / \mathrm{H}_{\mathrm{O}}$-based robust guaranteed cost control system design of an active suspension system for inwheel-independent-drive electric vehicles considering suspension performance requirements and parameter variation. In the active suspension system model, parameter uncertainties of active suspension are described by the bounded method, and the perturbation bounds can be also limited; then, the uncertain quarter-vehicle active suspension model where in-wheel motor is suspended as a dynamic vibration absorber is established. The robust guaranteed cost mixed $\mathrm{H}_{2} / \mathrm{H}_{\infty}$ feedback controller of the closed-loop active suspension system is designed using Lyapunov stability theory, in which the suspension working space, dynamic tire displacement, and the active control force are taken as $\mathrm{H}_{\infty}$ performance indices, the $\mathrm{H}_{2}$ norm of body acceleration is selected as the output performance index to be minimized, and then a comprehensive solution is transformed into a convex optimization problem with linear matrix inequality constraints. Simulations on random and bump road excitations are implemented to verify and evaluate the performance of the designed controller. The results show that the active suspension with developed robust mixed $\mathrm{H}_{2} / \mathrm{H}_{\infty}$ controller can effectively achieve better ride comfort and road-holding ability compared with passive suspension and alone $\mathrm{H}_{\infty}$ controller.
\end{abstract}

\section{Introduction}

Due to air pollution and the lack of fossil fuels, electric vehicles have developed rapidly in the world. The emerging in-wheel motor-driven electric vehicle (IWMD-EV) has become a promising vehicle architecture due to its advantages of low fuel consumption, less environmental pollution, clean electric power supply, and advanced vehicle dynamics control [1-3]. IWMD-EV uses hub motors to drive four wheels directly, which makes it easier to realize independent control and quick response of wheel torque, and provides greater flexibility and traffic mobility for the vehicle dynamic control (VDC) system. In order to improve the ride comfort and handling stability of vehicles, a great deal of research studies have been carried out on the VDC system in recent years, such as direct yaw moment control (DYC), active front steering system (AFS), traction control system (TCS), and regenerative braking system (RBS) [4-9].

Most of the above studies are focused on the lateral and longitudinal VDC systems, while optimization, design, and application of topology are still open and immaturate, and few research on the vertical vibration control of the IWMDEV active suspension system is carried out [10-13].In practice, the suspension system of IWMD-EV mounts and integrates the motor, wheel hub, and speed reducer together, which causes the increase of unsprung mass of IWMD-EV. It will lead to the deterioration of the ride comfort of the vehicle and even affect the active safety. Therefore, it is necessary to develop an advanced suspension topology based on IWM with a dynamic-damper mechanism. In addition, special attention should be paid to the active control of the IWMD-EV active suspension system. 
Robust control has been proved to be able to deal well with model uncertainties and external disturbances in practical engineering systems [14-27]. For instance, the work in [23] addressed the adaptive event-triggered neural control for nonaffine nonlinear multiagent systems. The unknown nonlinear function is approximated by radial basis function neural networks, and the unmodeled dynamics is also dealt with a dynamic signal. The integral barrier Lyapunov function-based adaptive control is adopted to solve the full state constraint problems for switched nonlinear systems [24].The distributed observer-based event-triggered bipartite tracking control is designed for stochastic nonlinear multiagent systems with input saturation, and a novel distributed reduced-order observer is constructed to estimate unknown states [25]. Some scholars have applied robust controller to active suspension dynamics systems, such as sliding mode control, fuzzy control, $H_{\infty}$ control, and other nonlinear adaptive robust methods [14-19, 26-28]. In [14], an integral terminal sliding mode control method with strong robustness is designed for the multivariable nonlinear suspension system affected by model uncertainty, timevarying parameters, road roughness excitation, and other factors so that the system could converge quickly in a finite time away from the equilibrium point. The work in [15] presents the adaptive fuzzy control for active suspension by considering time delay and unknown nonlinear dynamics, A predictor-based compensation scheme is developed, and a fuzzy logic system is constructed to address the two issues, respectively. The transient suspension response can be enhanced via the parameter estimation error-based finite-time adaptive method. In study [16], a sufficient condition for the design of sliding motion asymptotically stable is proposed, which can be transformed into a convex optimization problem, and an adaptive sliding mode controller is developed to ensure the reachability of the specified switch surface. Because $H_{\infty}$ control can well deal with the hard time-domain constraint problem of the suspension system, that is, on the premise of considering multiple constraint output indexes, it can maximize the suppression of vertical vibration, so the application of this method can better improve the ride comfort of suspension. For instance, the study in [17] introduced the auxiliary function-based integral inequality method and reciprocally convex approach into the $H_{\infty}$ controller design of the active half-vehicle suspension system with time-varying input delay, and the controller can achieve good performance. The research in [18] designed a robust $H_{\infty}$ controller for the electrorheological (ER) suspension system with sprung mass and time constant of the ER damper uncertainties, which achieved the expected performance. In [19], a multiobjective control with wheelbase preview information is presented for vehicle active suspension, in which disturbances of the front wheel are used as preview, and the solution is derived through cone complementarity linearization. The research [26] proposed the codesign problem of decentralized dynamic event-triggered communication and active suspension control of IWMD-EV. The T-S fuzzy active suspension model is established, and a novel decentralized dynamic event-triggered communication mechanism is also developed. In [27], the problem of event-triggered scheduling and control for active suspension over the resource-constrained controller area network (CAN) is addressed. Two new dynamic event-triggered schedulers (DETSs) are developed to orchestrate the transmissions of sensor data packets.

It is worth noting that, different from some published studies that aimed at traditional vehicle suspension, the main contribution of this work is to research a mixed $\mathrm{H}_{2}$ / $\mathrm{H}_{\infty}$-based robust guaranteed cost strategy of the active suspension system for in-wheel-independent-drive electric vehicles (IWMD-EV) rather than traditional vehicle suspension, where motor, the wheel hub, and speed reducer of IWMD-EV are mounted and integrated so that vehicle ride comfort will be deteriorated; meanwhile, designing the mixed $\mathrm{H}_{2} / \mathrm{H}_{\infty}$ robust guaranteed cost controller for such an active suspension system of IWMD-EV in Figure 1 is seldom treated; therefore, these theoretical design and results have the essential difference. The structure of this paper is arranged as follows: In Section 2, a quarter car suspension model of IWMD-EV is established. Section 3 presents the mixed $\mathrm{H}_{2} / \mathrm{H}_{\infty}$ robust guaranteed cost controller design. The simulation results are provided in Section 4. Finally, Section 5 gives the conclusion.

\section{Active Suspension System Model}

Since the main research objective is to design the control strategy of the active suspension system of IWMD-EV, we only consider the vertical motion of the active suspension system, and the lateral dynamics (sideslip, yaw, and roll) behaviour of the vehicle is ignored. As shown in Figure 1 [29], although the quarter-car model is relatively simple, it can feature the fundamental characteristics of the suspension system. It is noted that the half-vehicle suspension model or the whole vehicle suspension model can also describe vehicle vertical motion, pitch motion, and roll motion whereas it can be often used to analyze vehicle handling stability and study vehicle integrated suspension control.

According to the laws of dynamics, the quarter-car active suspension model can be described as

$$
\begin{array}{r}
Z_{s} m_{s}+k_{s}\left(Z_{s}-Z_{u}\right)+c_{s}\left(\dot{Z}_{s}-\dot{Z}_{u}\right)-F_{a}=0, \\
Z_{u} m_{u}-k_{s}\left(Z_{s}-Z_{u}\right)-c_{s}\left(\dot{Z}_{s}-\dot{Z}_{u}\right)+k_{t}\left(Z_{u}-Z_{r}\right)-k_{h}\left(Z_{h}-Z_{u}\right)-c_{h}\left(\dot{Z}_{h}-\dot{Z}_{u}\right)+F_{a}=0, \\
Z_{h} m_{h}+k_{h}\left(Z_{h}-Z_{u}\right)+c_{h}\left(\dot{Z}_{h}-\dot{Z}_{u}\right)=0,
\end{array}
$$




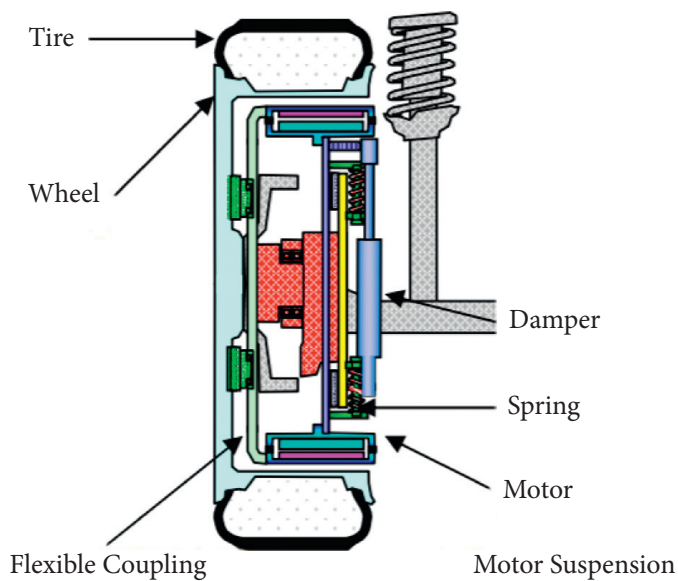

(a)

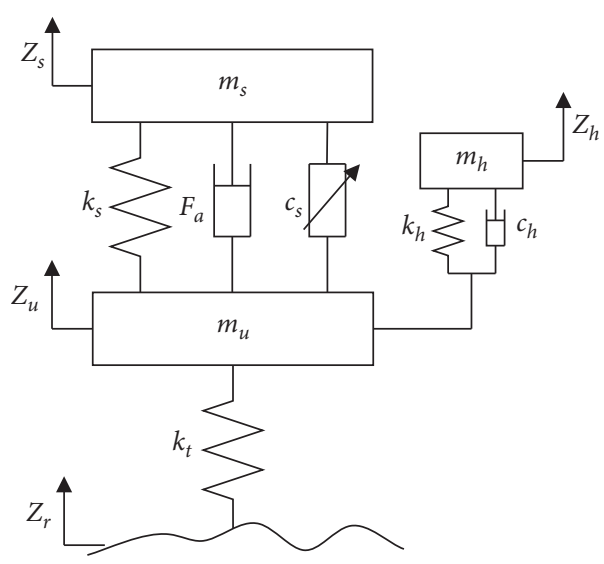

(b)

Figure 1: Quarter-car active suspension of IWMD-EV

[29]. (a). Mechanical structure. (b). Suspension model.

where $m_{s}, m_{u}$ and $m_{h}$ represent the sprung mass, the wheel mass, and the in-wheel-motor mass, respectively; $k_{s}$ and $c_{s}$ are the stiffness and damping of the suspension, respectively; $k_{h}$ and $c_{h}$ denote the stiffness and damping of the damping system between motor and wheel; $k_{t}$ is the tire stiffness; $F_{a}$ is the active control force; $Z_{s}, Z_{u}, Z_{h}$, and $Z_{r}$ denote the vertical displacement of the vehicle body, wheel, motor, and road, respectively; the superscripts "and "stand for velocity and acceleration, respectively.

In this suspension system, the sprung mass $m_{s}$ is an uncertain parameter due to the change of the vehicle load. For the convenience of the following description, let

$$
\begin{aligned}
& M_{s 0}=\frac{1}{m_{s 0}}, \\
& M_{s}=M_{s 0}\left(1+\alpha \delta_{M}(t)\right),
\end{aligned}
$$

where $m_{s 0}$ is the $m_{\mathrm{s}}$ nominal value of the sprung mass, and $\alpha$ represents the perturbation of the uncertain parameter with bound $\delta_{M}(t)<1$.

We choose the state variables of the active suspension system as follows:

$$
\begin{aligned}
& X_{1}=Z_{s}-Z_{u}, X_{2}=\dot{Z}_{s}, X_{3}=Z_{u}-Z_{r}, \\
& X_{4}=\dot{Z}_{u}, X_{5}=Z_{h}-Z_{r}, X_{6}=\dot{Z}_{h} .
\end{aligned}
$$

In the process of active suspension system designing, four performance indicators should be considered as follows:

(1) Ride comfort. Vertical acceleration of the body can be used as an evaluation index of ride comfort, which is generally required to be minimized.

(2) Suspension working space (SWS). Due to the structural limitation of the suspension itself, the excessive suspension travel will lead to collision, so it should be limited as

$$
Z_{s}-Z_{u} \ll S_{\max }
$$

(3) Steering stability. To satisfy the steering stability of the vehicle, it is required that the tires cannot leave the road in the process of driving. Obviously, only the dynamic load of the tire is less than the static load that satisfies the requirements. Otherwise, it may result in vibration of the driver seat in the vertical direction and cause the wheels to lift off the ground. That is,

$$
k_{t}\left(Z_{u}-Z_{r}\right)<M g \text {, }
$$

where

$$
M=m_{s}+m_{u}+m_{h} .
$$

(4) Active control force. The output control force of the actuating motor cannot be infinite and should be limited as

$$
\left|F_{a}\right| \ll F_{a \max } .
$$

We consider that $H_{\infty}$ control is good at the suppression of the energy bounded interference and has a good robustness, while $\mathrm{H}_{2}$ control has a significant effect on suppressing the white noise interference and has a good dynamic characteristic. Therefore, we take the body acceleration (BA) $\ddot{Z}_{s}$ as $H_{2}$ index and take the other three performances including the suspension working space, dynamic tire displacement(DTD), and the active control force as the $H_{\infty}$ index, that is,

$$
\begin{aligned}
z_{2} & =Z_{s}, \\
z_{\infty} & =\left[\frac{Z_{s}-Z_{u}}{S_{\max }} \frac{k_{t}\left(Z_{u}-Z_{r}\right)}{\left(m_{s}+m_{u}+m_{h}\right) g} \frac{F_{a}}{F_{a \max }}\right]^{T} .
\end{aligned}
$$

Combined with the above derivation and equation, the state space expression of the open loop suspension uncertain linear system is obtained as 


$$
\left\{\begin{array}{l}
\dot{x}(t)=(A+\Delta A) x(t)+B_{1} w(t)+\left(B_{2}+\Delta B_{2}\right) u(t), \\
z_{2}(t)=C_{2} x(t)+D_{2} u(t) \\
z_{\infty}(t)=C_{\infty} x(t)+D_{\infty} u(t)
\end{array}\right.
$$

where $A, B_{1}, B_{2}, C_{2}, D_{2}, C_{\infty}$, and $D_{\infty}$ are known constant matrices that describe the nominal system model of the suspension; $\Delta A$ and $\Delta B_{2}$ are unknown real matrices of appropriate dimensions that represent time-varying parameter uncertainties of the system model. These matrices can be presented as follows:

$$
\begin{aligned}
& A=\left[\begin{array}{cccccc}
0 & 1 & 0 & -1 & 0 & 0 \\
-k_{s} M_{s 0} & -c_{s} M_{s 0} & 0 & c_{s} M_{s 0} & 0 & 0 \\
0 & 0 & 0 & 1 & 0 & 0 \\
k_{s} / m_{u} & c_{s} / m_{u} & c_{s} / m_{u} & -\left(c_{s}+c_{h}\right) / m_{u} & k_{h} / m_{u} & c_{h} / m_{u} \\
0 & 0 & 0 & -1 & 0 & 1 \\
0 & 0 & 0 & c_{h} / m_{h} & -k_{h} / m_{h} & -c_{h} / m_{h}
\end{array}\right], \\
& \Delta A=\left[\begin{array}{cccccc}
0 & 0 & 0 & 0 & 0 & 0 \\
-k_{s} M_{s 0} \alpha \delta_{M} & -c_{s} M_{s 0} \alpha \delta_{M} & 0 & c_{s} M_{s 0} \alpha \delta_{M} & 0 & 0 \\
0 & 0 & 0 & 0 & 0 & 0 \\
0 & 0 & 0 & 0 & 0 & 0 \\
0 & 0 & 0 & 0 & 0 & 0 \\
0 & 0 & 0 & 0 & 0 & 0
\end{array}\right], \\
& B_{1}=\left[\begin{array}{llllll}
0 & 0 & -1 & 0 & 0 & 0
\end{array}\right]^{T} \text {, } \\
& B_{2}=\left[\begin{array}{llllll}
0 & M_{s 0} & 0 & -1 / m_{u} & 0 & 0
\end{array}\right]^{T}, \\
& \Delta B_{2}=\left[\begin{array}{lllllll}
0 & M_{s 0} \alpha \delta_{M} & 0 & 0 & 0 & 0
\end{array}\right]^{T}, \\
& C_{2}=\left[\begin{array}{lllllll}
-k_{s} M_{s 0}-c_{s} M_{s 0} & 0 & c_{s} M_{s 0} & 0 & 0
\end{array}\right] \text {, } \\
& D_{2}=\left[M_{s 0}\right] \text {, } \\
& C_{\infty}=\left[\begin{array}{cccccc}
1 / S_{\max } & 0 & 0 & 0 & 0 & 0 \\
0 & 0 & k_{t} / M g & 0 & 0 & 0 \\
0 & 0 & 0 & 0 & 0 & 0
\end{array}\right] \text {, } \\
& D_{\infty}=\left[\begin{array}{lll}
0 & 0 & 1 / F_{a \max }
\end{array}\right]^{T} \text {. }
\end{aligned}
$$

The uncertain matrices $\Delta A$ and $\Delta B_{2}$ can be expressed as

$$
\left[\Delta A(t) \Delta B_{2}(t)\right]=H \delta_{M}(t)\left[\begin{array}{ll}
E_{1} & E_{2}
\end{array}\right],
$$

where $H, E_{1}$, and $E_{2}$ are known real matrices of appropriate dimensions which represent the structural information of uncertain parameters, that is,

$$
\begin{aligned}
H & =\left[\begin{array}{llllll}
0 & 1 & 0 & 0 & 0 & 0
\end{array}\right]^{T}, \\
E_{1} & =\left[\begin{array}{llllll}
-\alpha k_{s} M_{s 0} & -\alpha c_{s} M_{s 0} & 0 & \alpha c_{s} M_{s 0} & 0 & 0
\end{array}\right], \\
E_{2} & =\left[\begin{array}{lll}
\alpha M_{s 0}
\end{array}\right] .
\end{aligned}
$$

And $\delta_{M}(t)$ is an unknown real time-varying matrix satisfying

$$
\delta_{M}^{T}(t) \delta_{M}(t) \leq I
$$

We suppose the state feedback control law is

$$
u(t)=K x(t) .
$$

By applying the control law (14), the open-loop system (9) is transformed into the following closed-loop system:

$$
\left\{\begin{array}{l}
\dot{x}(t)=\left(A_{c}+H \delta_{M}(t) E_{c}\right) x(t)+B_{1} w(t), \\
z_{2}(t)=C_{2 c} x(t) \\
z_{\infty}(t)=C_{\infty \circ} x(t)
\end{array}\right.
$$

where

$$
\begin{aligned}
A_{c} & =A+B_{2} K, \\
E_{c} & =E_{1}+E_{2} K, \\
C_{2 c} & =C_{2}+D_{2} K, \\
C_{\infty} & =C_{\infty}+D_{\infty} K .
\end{aligned}
$$

Let 


$$
\widetilde{A}_{c}=A_{c}+H \delta_{M}(t) E_{c} .
$$

The closed loop system (15) can be reduced as

$$
\left\{\begin{array}{l}
\dot{x}(t)=\tilde{A}_{c} x(t)+B_{1} w(t), \\
z_{2}(t)=C_{2 c} x(t), \\
z_{\infty}(t)=C_{\infty c} x(t) .
\end{array}\right.
$$

Remark 1. We note that the parameter uncertainties of the active suspension system can be described by the bounded method. It is reasonable to make this compromise in most cases; the reason is due to this bound that can be determined in advance through experiments or estimations [5, 9, 14-19]. If the method cannot be used, parameter uncertainties of active suspension can be dealt with advanced technology such as adaptive strategy and other techniques [9, 14-19], whereas making this characterization can greatly simplify controller design.

\section{Robust Mixed Controller Design}

The $H_{\infty}$ control method has good robust stability, but it is conservative. If all the performance indicators of IWMD-EV are considered as $H_{\infty}$ performance indicators, the BA of vehicle may not reach the ideal effect. The $\mathrm{H}_{2}$ control method can obtain superior dynamic performance but with poor robustness and stability. Therefore, we combine the advantages of the two control methods to design the mixed $\mathrm{H}_{2} / \mathrm{H}_{\infty}$ guaranteed cost controller so that the active suspension system of IWMD-EV not only has greater robust stability but also meets better robust performance requirements.

The mixed $H_{2} / H_{\infty}$ guaranteed cost control is to design a state feedback control law (14) for the closed-loop system (18) such that the following design criteria are satisfied as follows:

(i) The closed-loop control system (18) is asymptotically stable.

(ii) The closed-loop transfer function $G_{z_{\infty} \omega}(s)$ from $\omega(t)$ to $z_{\infty}(t)$ satisfies

$$
\left\|G_{z_{\infty} \omega}(s)\right\|_{\infty}<\gamma_{\infty},
$$

where

$$
\begin{aligned}
G_{z_{\infty} \omega}(s) & =\left(C_{1}+D_{12} K\right)\left(s I-\left(A+B_{2} K\right)\right)^{-1} B_{1}+D_{11}, \\
\left\|G_{z_{\infty} \omega}(s)\right\|_{\infty} & =\sup _{\omega} \sigma_{\max }\left\{G_{z_{\infty} \omega}(j \omega)\right\},
\end{aligned}
$$

where $\sigma_{\max }\{\cdot\}$ denotes the largest singular value, and $\gamma_{\infty}$ is a prespecified positive scalar.

(iii) The closed-loop transfer function $G_{z_{2} \omega}(s)$ from $\omega(t)$ to $z_{2}(t)$ satisfies

$$
\left\|G_{z_{2} \omega}(s)\right\|_{2} \leq \gamma_{2}
$$

If $\widetilde{A}_{c}$ is asymptotically stable, then $G_{z_{2} \omega}(s)_{2}$ can be expressed as

$$
\left\|G_{z_{2} \omega}(s)\right\|_{2}=\sup _{\delta_{M}(t)} \operatorname{tr}\left\{B_{1}^{T} \widetilde{P} B_{1}\right\}
$$

where $\widetilde{P}=\widetilde{P}^{T} \geq 0$ is obtained from the following Lyapunov equation:

$$
\widetilde{P} \widetilde{A}_{c}+\widetilde{A}_{c} \widetilde{P}+C_{2 c}^{T} C_{2 c}=0,
$$

where $\gamma_{2}$ represents the upper bound of $H_{2}$ performance index.

To design a controller that meets the above three conditions, we introduce the following two lemmas:

Lemma 1 (See [20]). Given the appropriate dimensions matrices $Y=Y^{T}, D$, and $E$, there is

$$
Y+D F E+E^{T} F^{T} D^{T}<0,
$$

for $F$ satisfies $F^{T} F<I$, if and only if there exists a positive scalar $\varepsilon$ such that

$$
Y+\varepsilon D D^{T}+\varepsilon^{-1} E^{T} E<0 .
$$

Lemma 2 (See [21]). For any matrices $X$ and $Y$ with appropriate dimensions, there is

$$
X^{T} Y+Y^{T} X \leq \beta X^{T} X+\beta^{-1} Y^{T} Y,
$$

for any $\beta>0$.

To design the mixed $H_{2} / H_{\infty}$ robust guaranteed cost control of active suspension, we present the main design process of this controller via the following theorem.

Theorem 1. For system (18) and a given scalar $\gamma_{\infty}>0, \widetilde{A}_{c}$ is asymptotically stable, and $G_{z_{\infty} \omega}(s)_{\infty}<\gamma_{\infty}$ if and only if there exist two positive scalars $\varepsilon$ and $\beta$ such that the following inequality,

$$
\begin{aligned}
A_{c}^{T} P & +P A_{c}+P\left(\varepsilon H H^{T} P+\beta \gamma_{\infty}^{-2} B_{1} B_{1}^{T}\right) P \\
& +\varepsilon^{-1} E_{c}^{T} E_{c}+\beta^{-1} C_{\infty c}^{T} C_{\infty c}+C_{2 c}^{T} C_{2 c}<0,
\end{aligned}
$$

has a symmetric positive definite solution P. Furthermore, for the allowable parameter uncertainty,

$$
P \geq \widetilde{P} \geq 0,
$$

where $\widetilde{P}$ is obtained from (23).

Proof. According to the strict bounded real lemma, if and only if there exists a symmetric positive definite matrix $Q$ satisfying 


$$
\widetilde{A}_{c}^{T} Q+Q \widetilde{A}_{c}+\gamma_{\infty}^{-2} Q B_{1} B_{1}^{T} Q+C_{\infty c}^{T} C_{\infty c}<0,
$$

then $\widetilde{A}_{c}$ is asymptotically stable and $G_{z_{\infty} \omega}(s)_{\infty}<\gamma_{\infty}$.

And if there is a positive scalar $\beta$, (32) can be equivalent to

$$
\widetilde{A}_{c}^{T} Q+Q \widetilde{A}_{c}+\gamma_{\infty}^{-2} Q B_{1} B_{1}^{T} Q+C_{\infty c}^{T} C_{\infty \circ}+\beta C_{2 c}^{T} C_{2 c}<0 .
$$

By substituting (8) and letting $P=\beta^{-1} Q$, inequality (29) can be rewritten as

$$
\begin{aligned}
A_{c}^{T} P & +E_{c}^{T} \delta_{M}^{T} H^{T} P+P A_{c}+P H \delta_{M} E_{c} \\
& +\beta \gamma_{\infty}^{-2} P B_{1} B_{1}^{T} P+\beta^{-1} C_{\infty c}^{T} C_{\infty c}+C_{2 c}^{T} C_{2 c}<0 .
\end{aligned}
$$

In the light of Lemma 1, the matrix inequality (31) holds for all unknown real matrices $\delta_{M}$ satisfying $\delta_{M}^{T} \delta_{M}<I$ if and only if there exists $\varepsilon>0$ such that

$$
\begin{aligned}
A_{c}^{T} P & +P A_{c}+\beta \gamma_{\infty}^{-2} P B_{1} B_{1}^{T} P+\beta^{-1} C_{\infty \circ}^{T} C_{\infty c} \\
& +C_{2 c}^{T} C_{2 c}+\varepsilon P H H^{T} P+\varepsilon^{-1} E_{c}^{T} E_{c}<0 .
\end{aligned}
$$

Obviously, (32) is equivalent to (27).

Furthermore, let

$$
J=\varepsilon P H H^{T} P+\varepsilon^{-1} E_{c}^{T} E_{c}-P H \delta_{M} E_{c}-E_{c}^{T} \delta_{M}^{T} H^{T} P .
$$

According to Lemma 2 and inequality (13) such that

$$
\begin{aligned}
P H \delta_{M} E_{c}+E_{c}^{T} \delta_{M}^{T} H^{T} P & \leq \varepsilon^{-1} E_{c}^{T} E_{c}+\varepsilon P H \delta_{M} \delta_{M}^{T} H^{T} P \\
& \leq \varepsilon^{-1} E_{c}^{T} E_{c}+\varepsilon P H H^{T} P .
\end{aligned}
$$

Therefore, $J \geq 0$.

Then, by subtracting (23) from (32), we obtain

$$
\begin{gathered}
\widetilde{A}_{c}^{T}(P-\widetilde{P})+(P-\widetilde{P}) \widetilde{A}_{c}+\beta \gamma_{\infty}^{-2} P B_{1} B_{1}^{T} P \\
+\beta^{-1} C_{\infty c}^{T} C_{\infty \circ}+C_{2 c}^{T} C_{2 c}+J<0 .
\end{gathered}
$$

Since $\widetilde{A}_{c}$ is asymptotically stable, and

$$
J+\beta \gamma_{\infty}^{-2} P B_{1} B_{1}^{T} P+\beta^{-1} C_{\infty c}^{T} C_{\infty \subset c} \geq 0 .
$$

We can get $P^{\sim} \leq P$ directly from Lyapunov stability theory. Hence, Theorem 1 has been proved.

Furthermore, the solution $P$ guarantees the worst-case $\mathrm{H}_{2}$ performance index satisfying

$$
\left\|G_{z_{2} \omega}(s)\right\|_{2} \leq \gamma_{2}
$$

where

$$
\gamma_{2}=\operatorname{tr}\left(B_{1}^{T} P B_{1}\right)
$$

Theorem 2. For system (18) and a given scalar $\gamma_{\infty}>0$, there exists a feedback control law $u(t)=K x(t)$ such that the design criteria ( $i$ ) and (ii) are satisfied if and only if there exists two positive scalars $\varepsilon$ and $\beta$. A symmetric positive definite matrix $X$ and a matrix $Y$ such that

$$
\left[\begin{array}{cccc}
W & * & * & * \\
N_{1} & -\varepsilon I & * & * \\
N_{2} & 0 & -\beta I & * \\
N_{3} & 0 & 0 & -I
\end{array}\right]<0,
$$

where

$$
\begin{aligned}
W & =\left(A X+B_{2} Y\right)^{T}+A X+B_{2} Y+\varepsilon H H^{T}+\beta \gamma^{-2} B_{1} B_{1}^{T}, \\
N_{1} & =E_{1} X+E_{2} Y, \\
N_{2} & =C_{\infty} X+D_{\infty} Y, \\
N_{3} & =C_{2} X+D_{2} Y .
\end{aligned}
$$

Furthermore, if (32) has a feasible solution $(\varepsilon, \beta, X, Y)$, then the control law $K=Y X^{-1}$.

Proof. According to Theorem 1, there exists a feedback control law (14) that satisfies the design criteria (i) and (ii) if and only if there exists two scalars $\varepsilon$ and $\beta$, and a symmetric positive definite matrix is $P$ such that the matrix inequality (27) holds

By multiplying both sides of (21) by $P^{-1}$, we obtain

$$
\begin{aligned}
P^{-1} A_{c}^{T} & +A_{c} P^{-1}+\varepsilon H H^{T} P+\beta \gamma_{\infty}^{-2} B_{1} B_{1}^{T}+\varepsilon^{-1} P^{-1} E_{c}^{T} E_{c} P^{-1} \\
& +\beta^{-1} P^{-1} C_{\infty c}^{T} C_{\infty} P^{-1}+P^{-1} C_{2 c}^{T} C_{2 c} P^{-1}<0 .
\end{aligned}
$$

Using the Schur complement [22], we yield

$$
\left[\begin{array}{cccc}
\bar{W} & * & * & * \\
\bar{N}_{1} & -\varepsilon I & * & * \\
\bar{N}_{2} & 0 & -\beta I & * \\
\bar{N}_{3} & 0 & 0 & -I
\end{array}\right]<0,
$$

where

$$
\begin{aligned}
\bar{W} & =P^{-1}\left(A+B_{2} K\right)^{T}+\left(A+B_{2} K\right) P^{-1}+\varepsilon H H^{T}+\beta \gamma^{-2} B_{1} B_{1}^{T}, \\
\bar{N}_{1} & =\left(E_{1}+E_{2} K\right) P^{-1}, \\
\bar{N}_{2} & =\left(C_{\infty}+D_{\infty} K\right) P^{-1}, \\
\bar{N}_{3} & =\left(C_{2}+D_{2} K\right) P^{-1} .
\end{aligned}
$$

Defining $X=P^{-1}$ and $Y=K P^{-1}$, the matrix inequality (42) can be easily reduced to (39). This proves Theorem 2.

Theorem 2. provides the characterization of all controllers that guarantee the realization of design criteria (i) and (ii), while (39) provides a $\mathrm{H}_{2} / \mathrm{H}_{\infty}$ guaranteed cost up bound $\operatorname{tr}\left(B_{1}^{T} P B_{1}\right)$. Therefore, we can use this representation to design the desired mixed $H_{2} / H_{\infty}$ guaranteed cost controller. 
Theorem 3. We consider system (8) and a given scalar $\gamma_{\infty}>0$, if following linear convex optimization problem

$$
\begin{aligned}
& \min _{\varepsilon, \beta, X, Y, N} \operatorname{tr}(N) \\
& \text { s.t. } \\
& \text { (a). (32), } \\
& \text { (b). }\left[\begin{array}{cc}
-N & B_{1}^{T} \\
B_{1} & -X
\end{array}\right]<0,
\end{aligned}
$$

has a set of possible solutions $(\varepsilon, \beta, X, Y, N)$, then $u(t)=$ $Y X^{-1} x(t)$ is the mixed $H_{2} / H_{\infty}$ guaranteed cost control law of the active suspension system, and the upper bound of $\mathrm{H}_{2}$ performance index is $\gamma_{2}=\operatorname{tr}(N)$.

Proof. According to Theorem 2, the control law constructed from any feasible solution of problem (39) satisfies the design criteria (i) and (ii).

In the light of Schur complement lemma, the constraint condition (b) of convex optimization problem (44) is equivalent to

$$
B_{1}^{T} X^{-1} B_{1}<N .
$$

So, minimizing $\operatorname{tr}(N)$ is equal to minimizing the upper bound of $\mathrm{H}_{2}$ performance index $\gamma_{2}$. Due to the convexity of the objective function and constraints, the optimization problem (44) can achieve global optimality. Thus, the proof is completed.

Through Theorem 2 and Theorem 3, the design of mixed $\mathrm{H}_{2} / \mathrm{H}_{\infty}$ guaranteed cost control law is realized, which not only ensures the asymptotic stability of the closed-loop system (18) but also satisfies $G_{z_{\infty} \omega}(s)_{\infty}<\gamma_{\infty}$ when the disturbance attenuation level $\gamma_{\infty}$ is given; that is, the SWS constraint, DTD constraint, and active control force have certain safety constraints under external disturbance; moreover, $\gamma_{2}$ is minimized; that is, the $\mathrm{BA}$ is minimized under external disturbance.

Remark 2. We note that perhaps this combination of the $\mathrm{H}_{2}$ method is not proposed for the first time, while this mixed $\mathrm{H}_{2} / \mathrm{H}_{\infty}$ guaranteed cost control method is particularly designed for active suspension of in-wheel-drive electric vehicles. Also, the proposed method can be extended to other vehicle dynamics control systems when multicontrol objectives in VDC systems are oriented by applying this mixed $H_{2} / H_{\infty}$ guaranteed cost control strategy and framework.

\section{Simulation and Analysis}

The nominal values of parameters for the active suspension system in IWMD-EV are shown in Table 1. The sprung mass $m_{s}$ is an uncertain parameter with a range of [40 kg, $60 \mathrm{~kg}$ ], i.e., the perturbation value $\alpha=0.16$.

We use LMI toolbox of MATLAB to solve the mixed $\mathrm{H}_{2} / \mathrm{H}_{\infty}$ guaranteed cost state feedback control law for the active suspension system. Figure 2 shows the relationship between the disturbance attenuation level $\gamma_{\infty}$ and the $H_{2}$ guaranteed performance index $\gamma_{2}$ of the closed-loop suspension system.

As can be seen from Figure 2, $\gamma_{2}$ increases gradually with the decrease of $\gamma_{\infty}$, and when $\gamma_{\infty}$ approaches the minimum value, $\gamma_{2}$ increases rapidly. Combining the two performance indexes, when we take $\gamma_{\infty}=15$, the corresponding $\gamma_{2}$ and controller are as follows:

$$
\begin{aligned}
\gamma_{2} & =8.6743 \\
K & =10^{4} \times\left[\begin{array}{llllll}
1.6538 & -0.0158 & -0.1448 & -0.1399 & -0.0001 & -0.0000
\end{array}\right] \\
K & =10^{4} \times\left[\begin{array}{llllll}
1.6538 & -0.0158 & -0.1448 & -0.1399 & -0.0001 & -0.0000
\end{array}\right]
\end{aligned}
$$

For comparison, optimizing all outputs as $H_{\infty}$ performance indexes, we design a constrained $H_{\infty}$ controller as

$$
K_{c o n}=10^{4} \times\left[\begin{array}{llllll}
1.1293 & -0.1084 & 9.6321 & 0.0748 & -0.6461 & -0.1400
\end{array}\right]
$$

Here, we note that the constrained $H_{\infty}$ control for the active suspension of IWMD-EV is only used to compare the performance of the proposed controller, and the detailed design process is omitted for brevity. Interested readers can refer to related papers such as Refs [17-19] for $H_{\infty}$ design of the suspension system. Besides, the solution time of proposed mixed $\mathrm{H}_{2} / \mathrm{H}_{\infty}$ guaranteed cost controller can be executed offline, so the total computational load can be tolerated for vehicle engineering application equipped with advanced hardware and processor.

4.1. Power Spectral Density Analysis. To obtain the frequency performance of the active suspension, power spectral density (PSD) analysis is performed based on the data obtained from random road simulation. The results are shown in 
TABLE 1: Nominal value of active suspension parameters.

\begin{tabular}{lccc}
\hline Parameter & Value & Parameter & Value \\
\hline$m_{s}$ & $320 \mathrm{Kg}$ & $m_{u}$ & $40 \mathrm{Kg}$ \\
$k_{s}$ & $18000 \mathrm{~N} / \mathrm{m}$ & $m_{h}$ & $20 \mathrm{Kg}$ \\
$k_{t}$ & $220000 \mathrm{~N} / \mathrm{m}$ & $C_{h}$ & $1000 \mathrm{~N} \cdot \mathrm{s} / \mathrm{m}$ \\
$C_{s}$ & $1400 \mathrm{~N} \cdot \mathrm{s} / \mathrm{m}$ & $k_{h}$ & $15000 \mathrm{~N} / \mathrm{m}$ \\
\hline
\end{tabular}

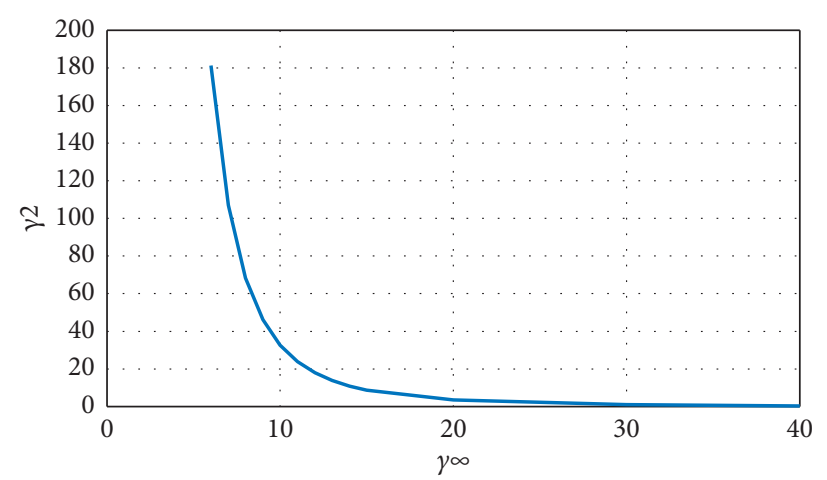

Figure 2: $\gamma_{2}-\gamma_{\infty}$, the relationship between $\gamma_{2}$ and $\gamma_{\infty}$.

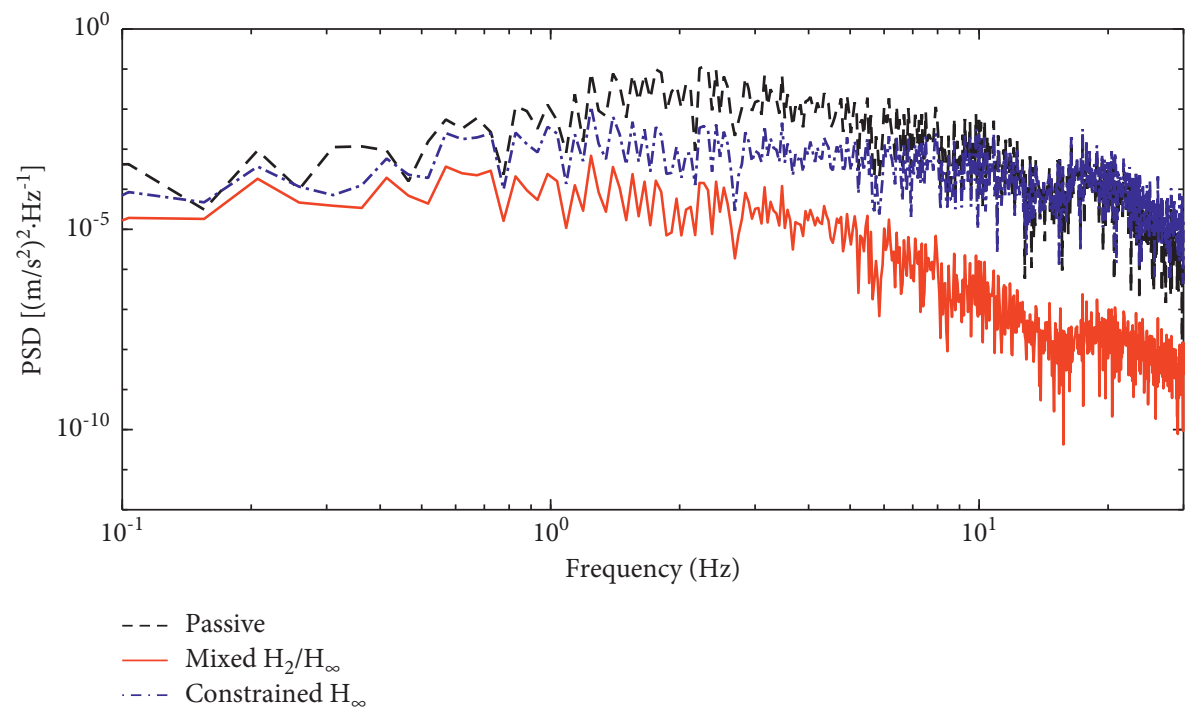

FIgURE 3: Power spectral density analysis of body acceleration.

Figures 3-5. As can be seen from these figures, the BA power spectral density of the mixed robust $H_{2} / H_{\infty}$ guaranteed cost controller for active suspension is the minimum at the full frequency, which indicates that the corresponding controller has a good performance of suppressing vertical vibration. In the low frequency range of $0.1-5 \mathrm{~Hz}$, the DTD power spectral density of the active suspension with mixed robust $\mathrm{H}_{2} / \mathrm{H}_{\infty}$ guaranteed cost is also better than that of passive suspension and constrained $H_{\infty}$ with active suspension. In terms of the SWS, although the two active suspension systems are slightly higher than the passive suspension in the low frequency range of $0.1-2 \mathrm{~Hz}$, they are basically the same as the passive suspension in the high frequency. The power spectral density analysis reveals that the designed mixed robust $H_{2} / H_{\infty}$ guaranteed cost controller possesses better passenger comfort and road holding ability.

4.2. Random Road Response. Firstly, the C-level road is selected as the system input, that is,

$$
\dot{Z}_{r}(t)=-2 \pi n_{0} Z_{r}(t)+2 \pi n_{0} \sqrt{G_{Z_{r}}\left(n_{0}\right) u} \cdot \omega(t),
$$

where $n_{c}=0.01 m^{-1}$ is the lower cut-off space frequency; $\omega(t)$ is the Gaussian white noise with an average of $0 ; Z_{r}$ is the vertical displacement of road surface; $u=20 \mathrm{~m} / \mathrm{s}$ denotes the velocity of vehicle; $G_{z_{r}}\left(n_{0}\right)=64 \times 10^{-6} \mathrm{~m}^{3}$ is the coefficient of road roughness. 


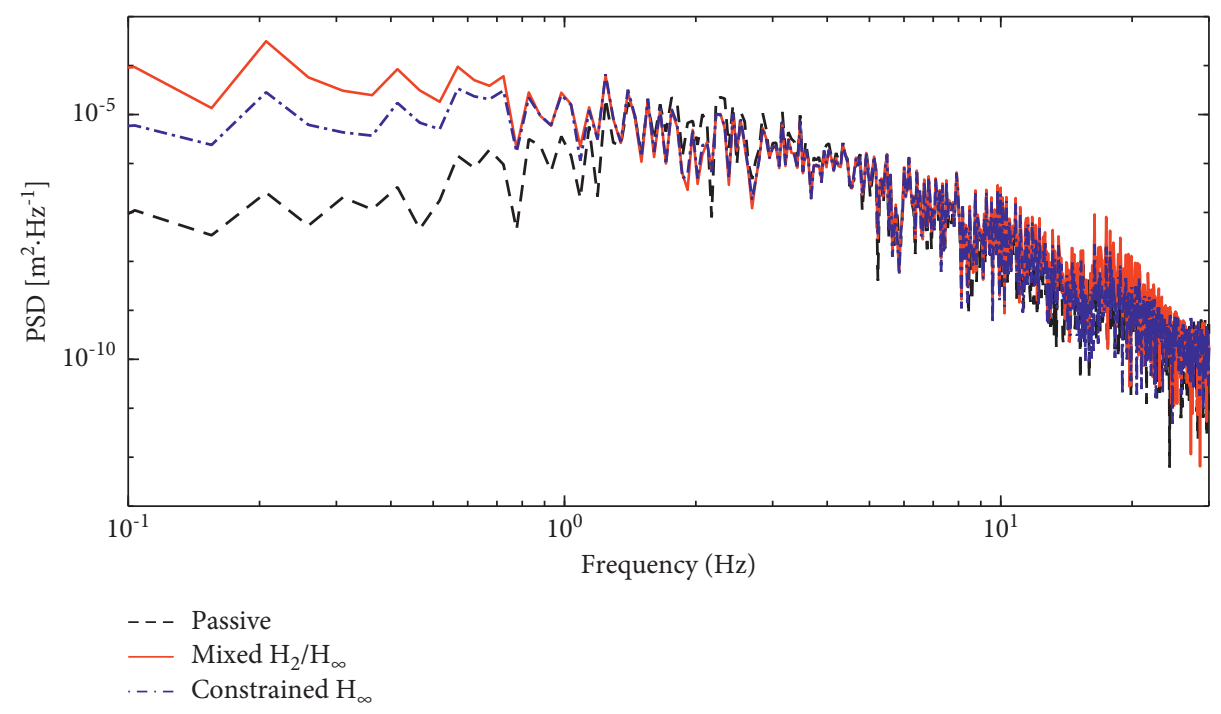

FIGURE 4: Power spectral density analysis of suspension working space.

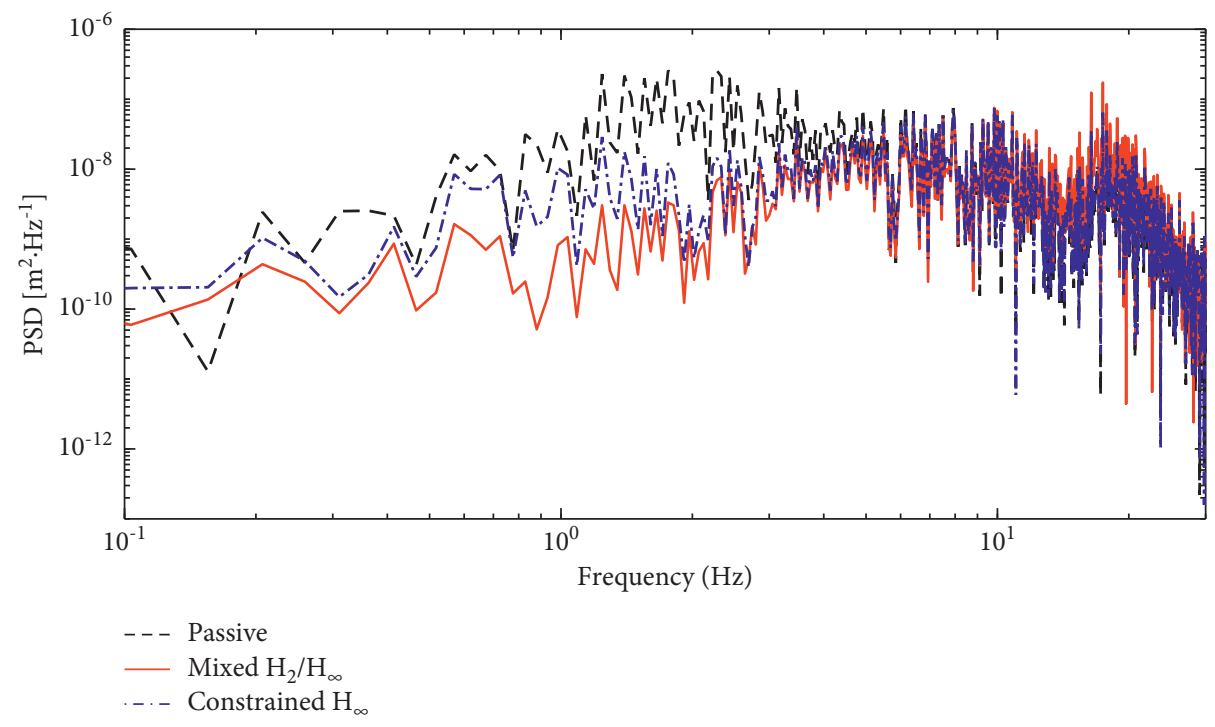

Figure 5: Power spectral density analysis of dynamic tire displacement.

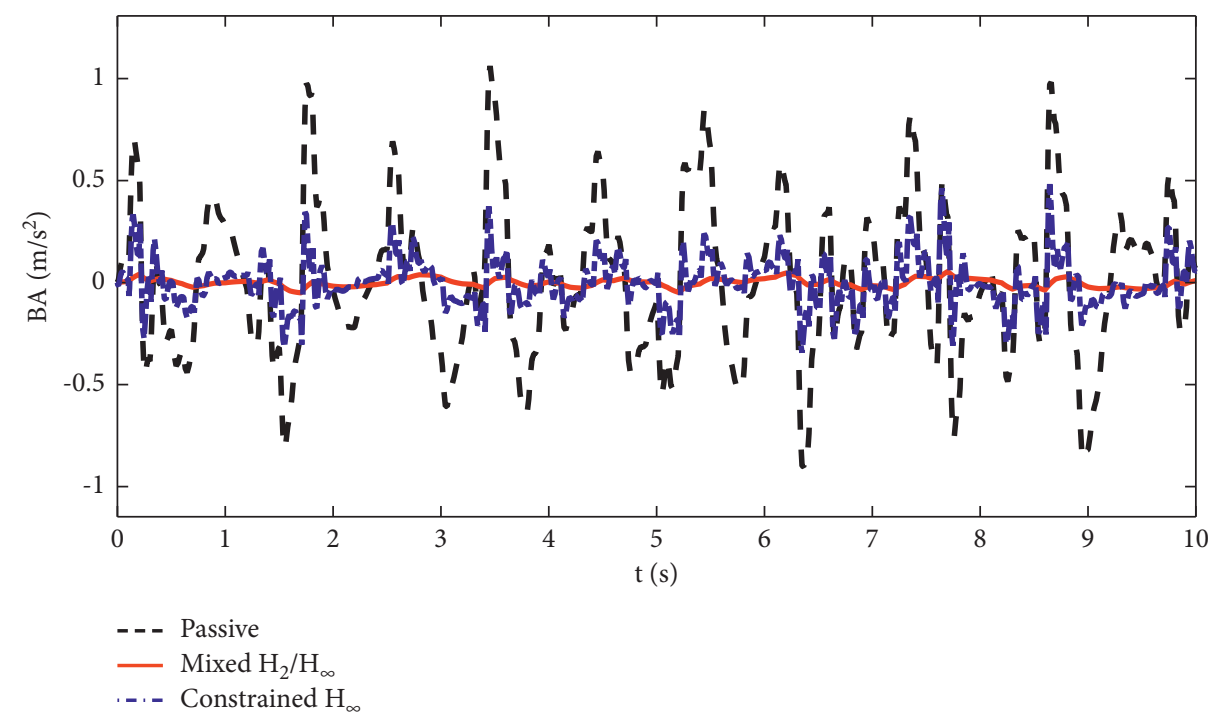

FIGURE 6: Random road body acceleration responses of nominal suspension. 


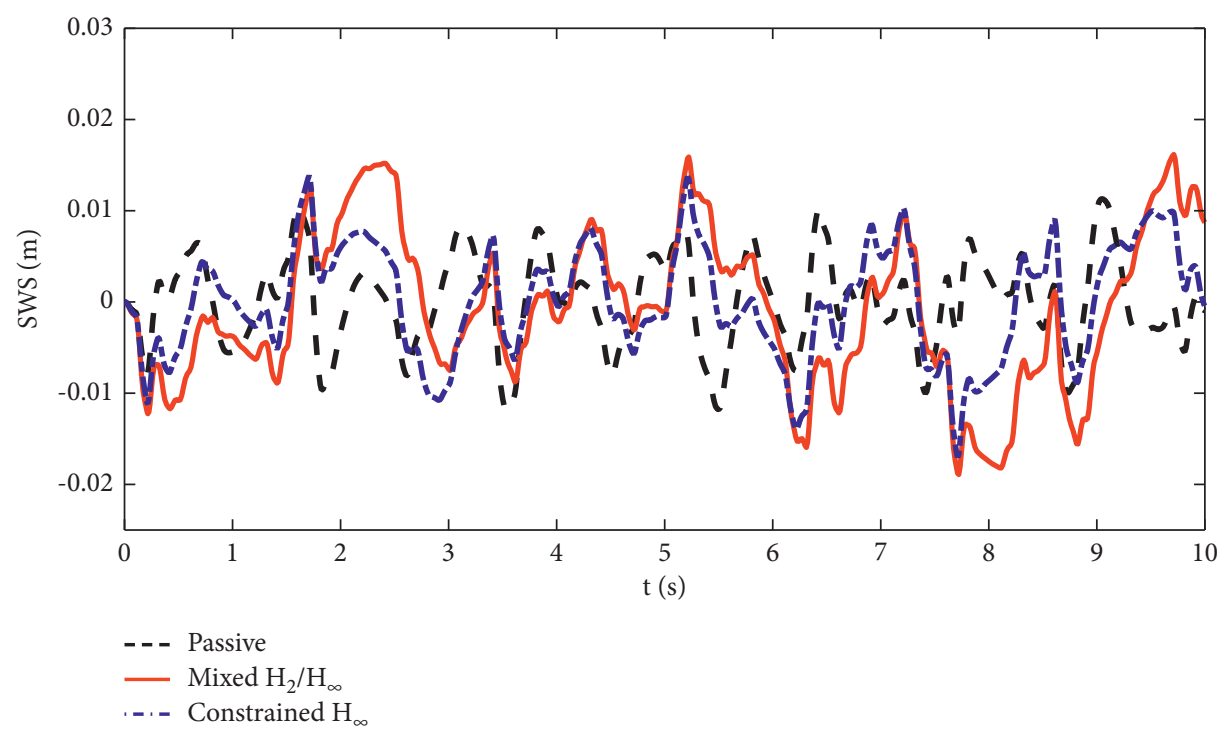

FIGURE 7: Random road working space responses of nominal suspension.

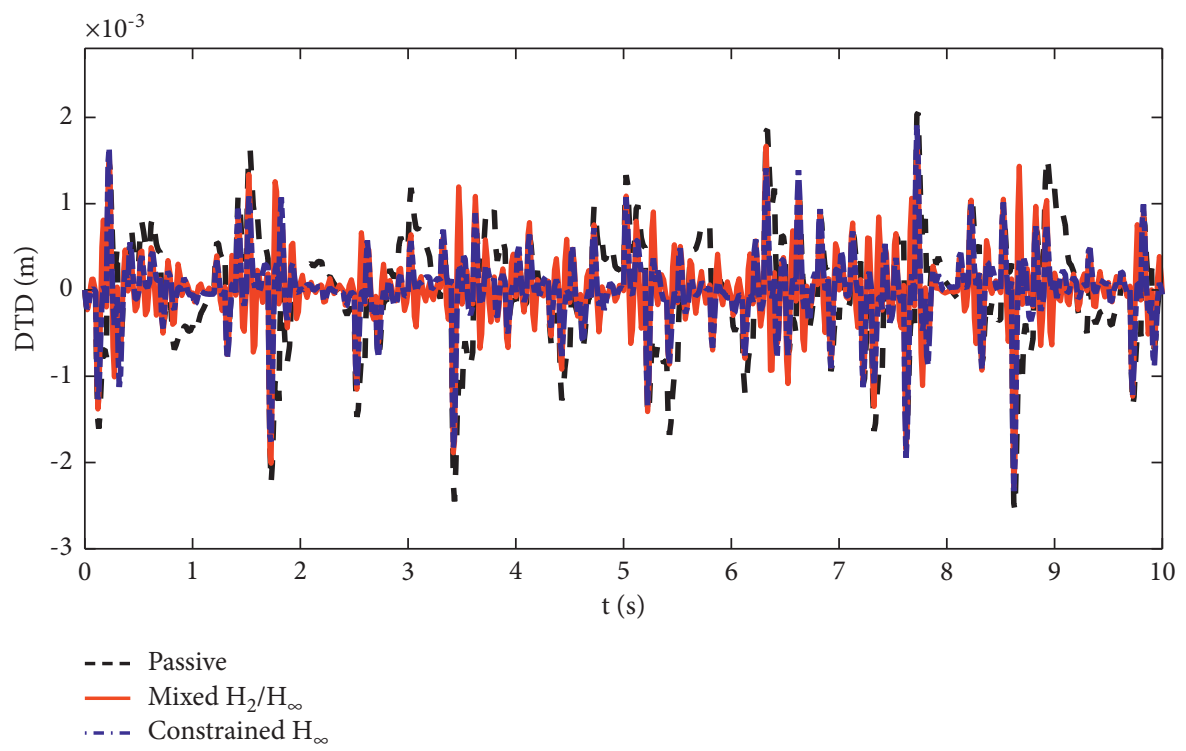

Figure 8: Random road dynamic tire displacement responses of nominal suspension.

Three random road responses of nominal suspension systems are illustrated in Figures 6-11. As shown in these figures, both active suspensions achieve better body acceleration performance, and the mixed robust $\mathrm{H}_{2} / \mathrm{H}_{\infty}$ guaranteed cost controller is better than the constrained $H_{\infty}$ controller. Compared with the passive suspension, the suspension working space of the two active suspensions is slightly worse but still within the acceptable range. This is because the SWS and the BA are a pair of contradictory performance. The dynamic tire displacement performance of the two active suspension is similar, which is smaller than that of the passive suspension.
4.3. Bump Road Response. The bump road excitation is selected as the second input road; it can be described as

$$
Z_{r}(t)=\frac{h}{2}\left(1-\cos \left(\frac{2 \pi u}{L} t\right)\right)
$$

where $v$ is the vehicle velocity; $L$ and $h$ are the length and height of the bump, respectively. Here, we take $v=45 \mathrm{~km} / h$, $L=5 m$, and $h=0.1 m$.

Figures 12-14 are the simulation results of the three performance indicators of the nominal suspension and Figures 15-17 are the simulation results of the perturbation suspension with $40 \mathrm{~kg}$ variation of the sprung mass. As can 


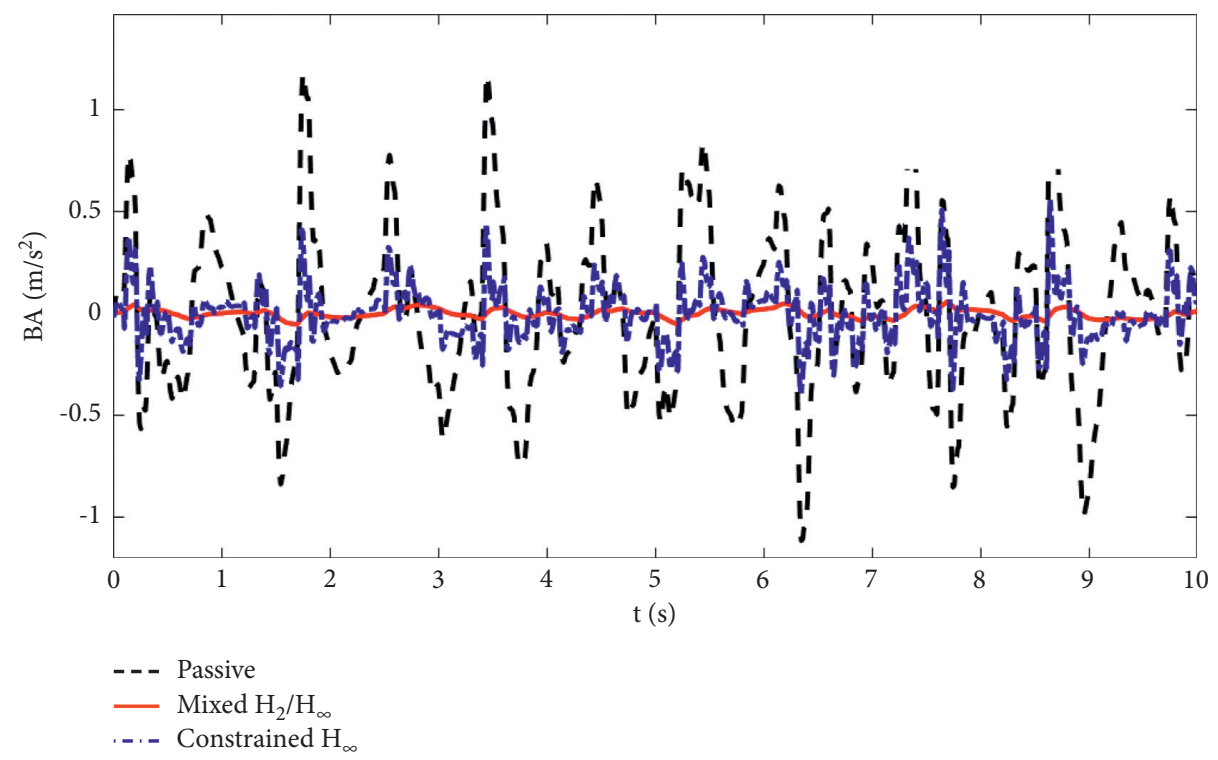

FIGURE 9: Random road body acceleration responses of suspension with parameter variation.

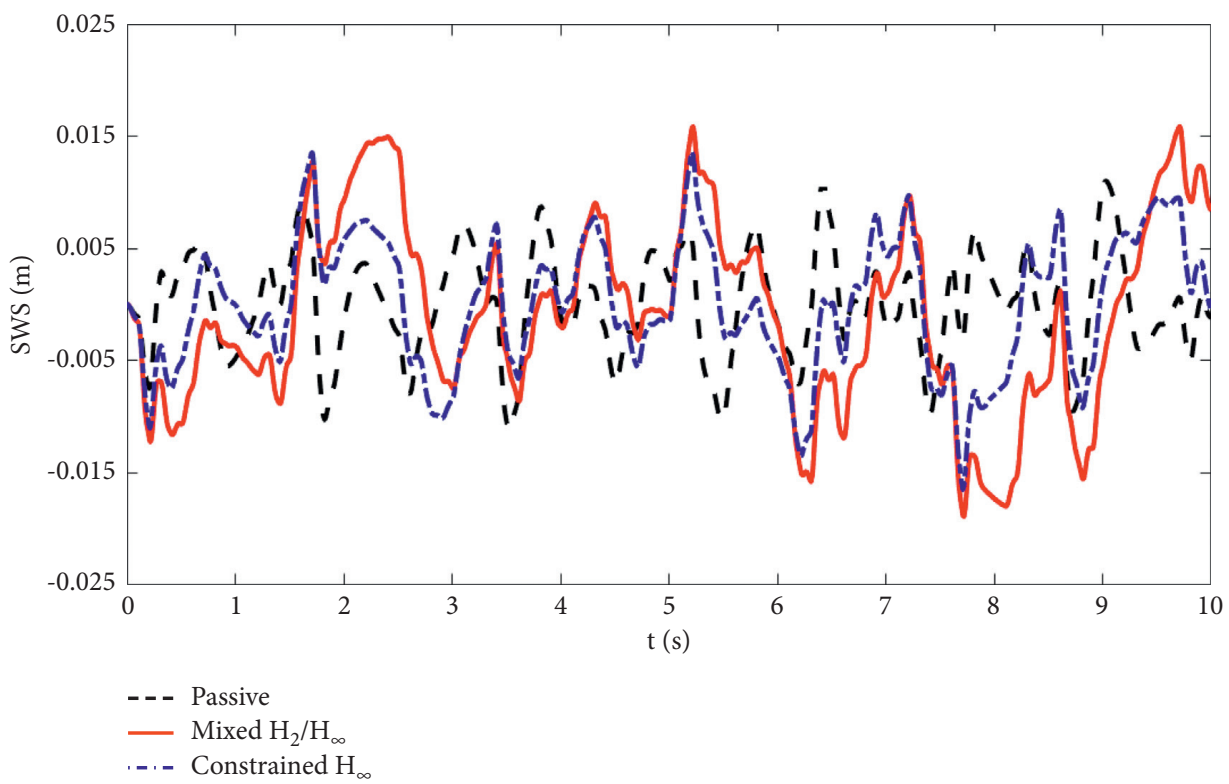

FIGURE 10: Random road working space responses of suspension with parameter variation.

be seen from these figures, the BA and the DTD performances of two active suspensions are much better than the passive suspension, and the mixed robust $H_{2} / H_{\infty}$ guaranteed cost control suspension has the best performance. Although the SWS performance of two active suspensions is deteriorated, it remained within the constraint range (less than $\pm 0.1 \mathrm{~m}$ ). In addition, the response of the perturbation model shows that the mixed robust $H_{2} / H_{\infty}$ guaranteed cost controller has good robustness compared with alone $\mathrm{H}_{\infty}$ controller. 


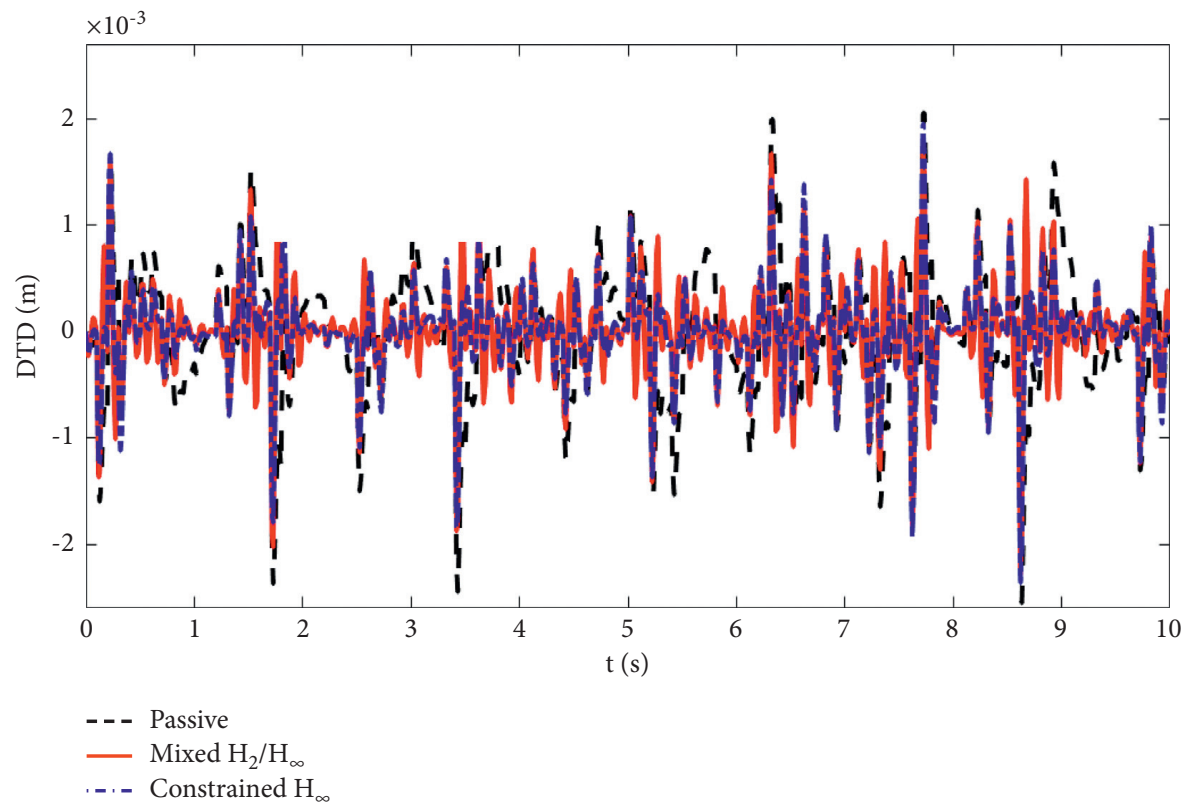

FIgURE 11: Random road dynamic tire displacement responses of suspension with parameter variation.

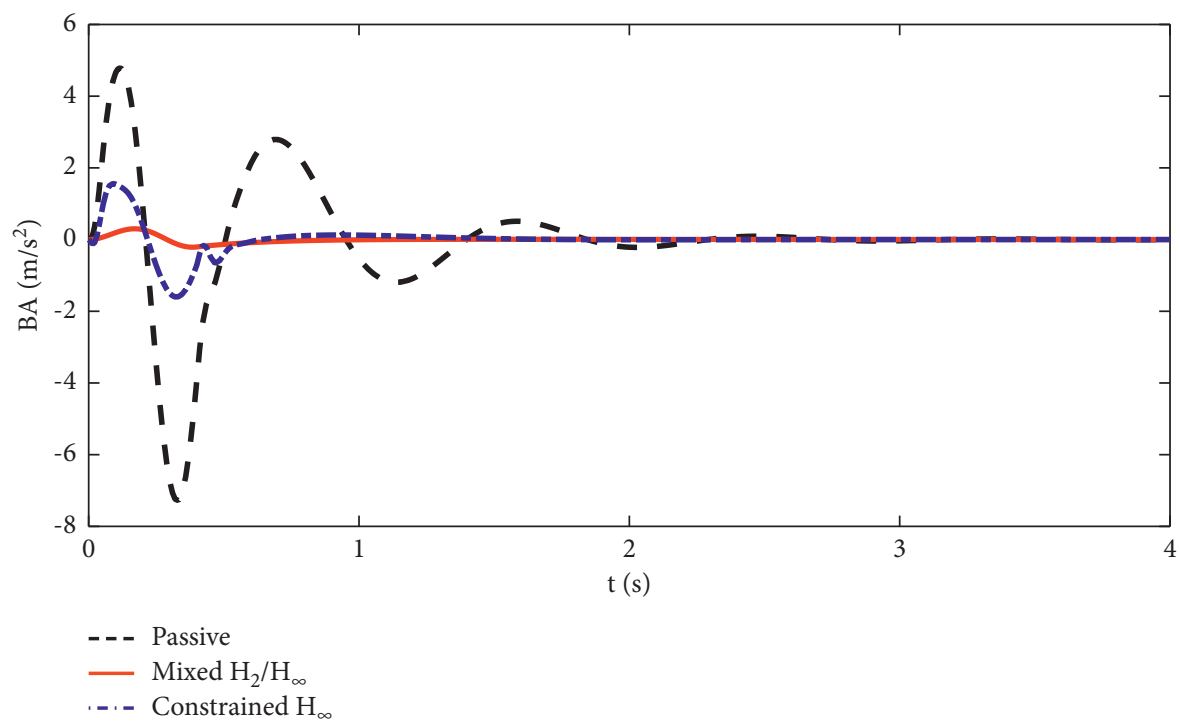

FigURE 12: Bump body acceleration responses of nominal suspension. 


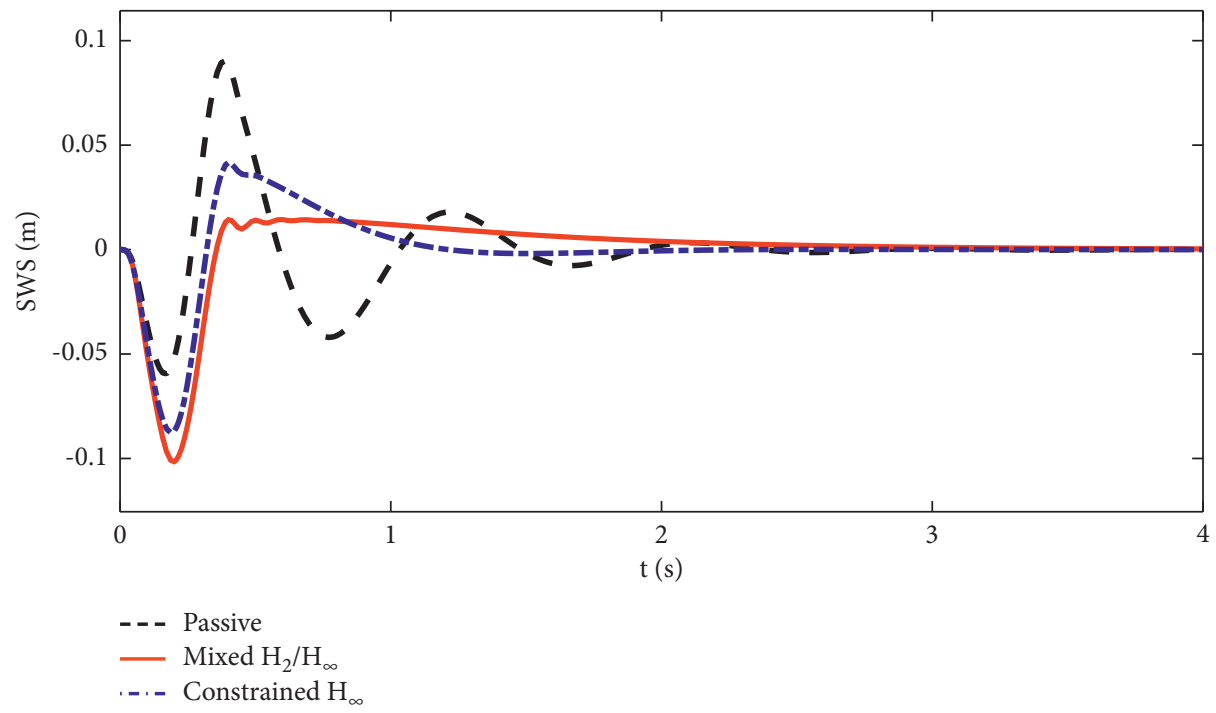

FIGURE 13: Bump working space responses of nominal suspension.

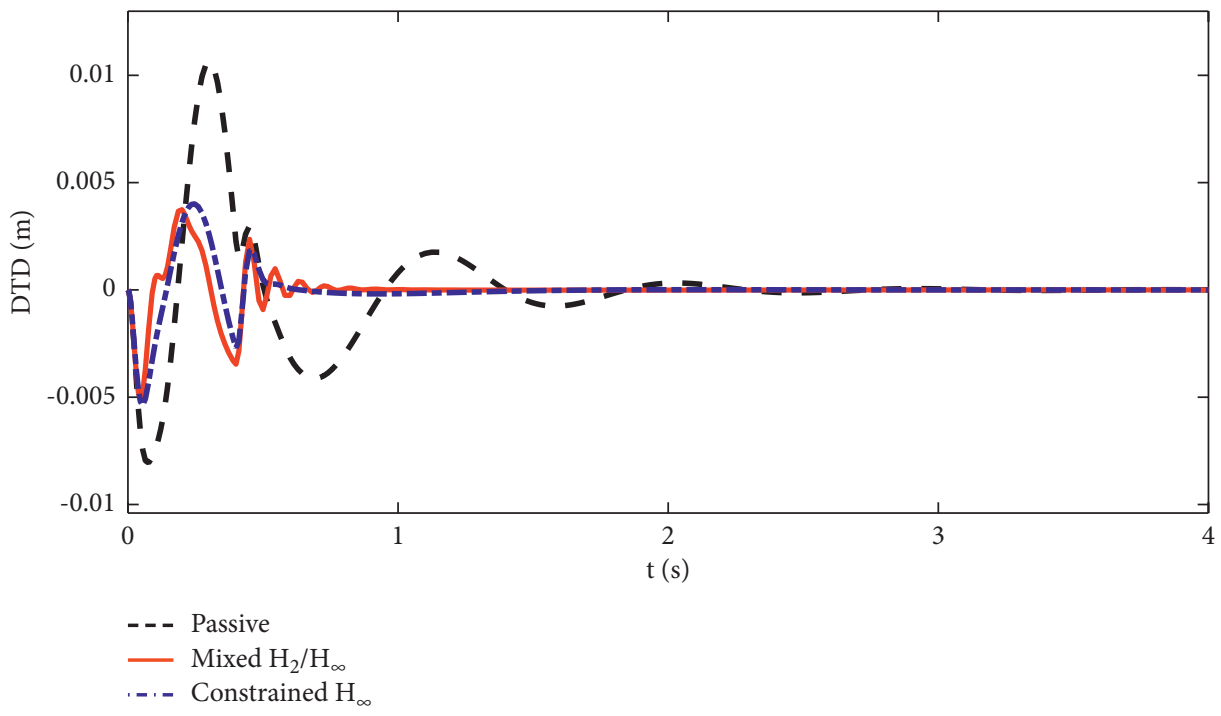

Figure 14: Bump dynamic tire displacement responses of nominal suspension. 


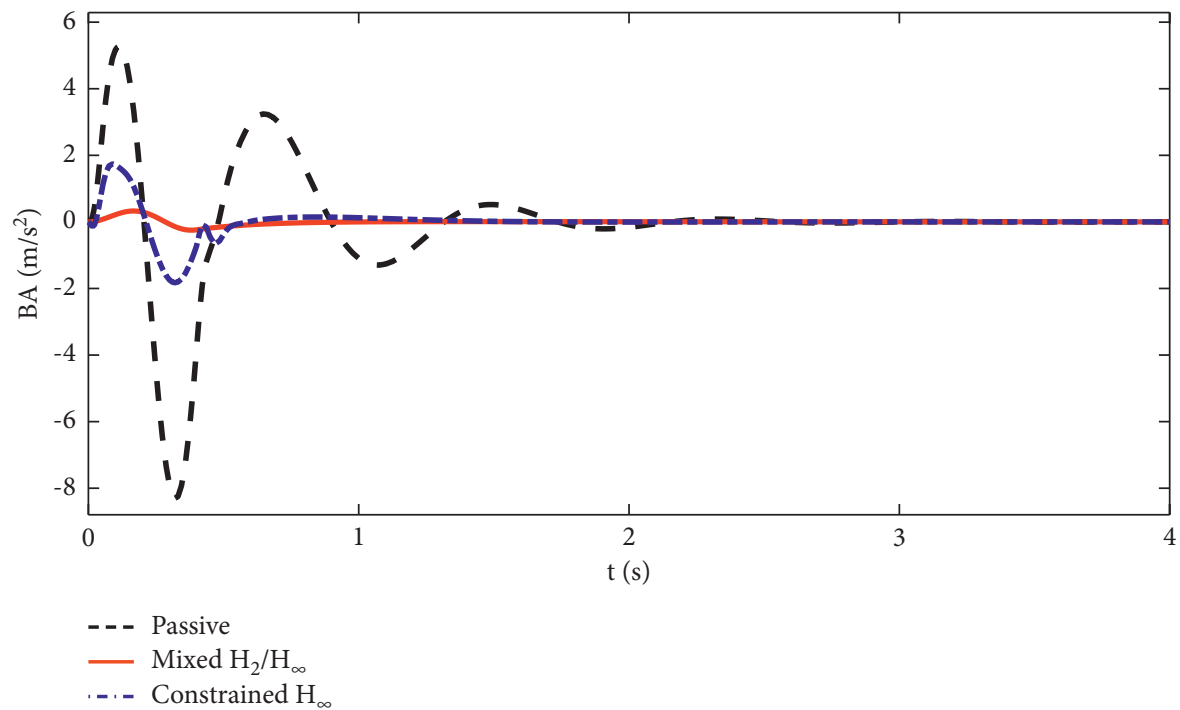

FIGURE 15: Bump body acceleration responses of suspension with parameter variation.

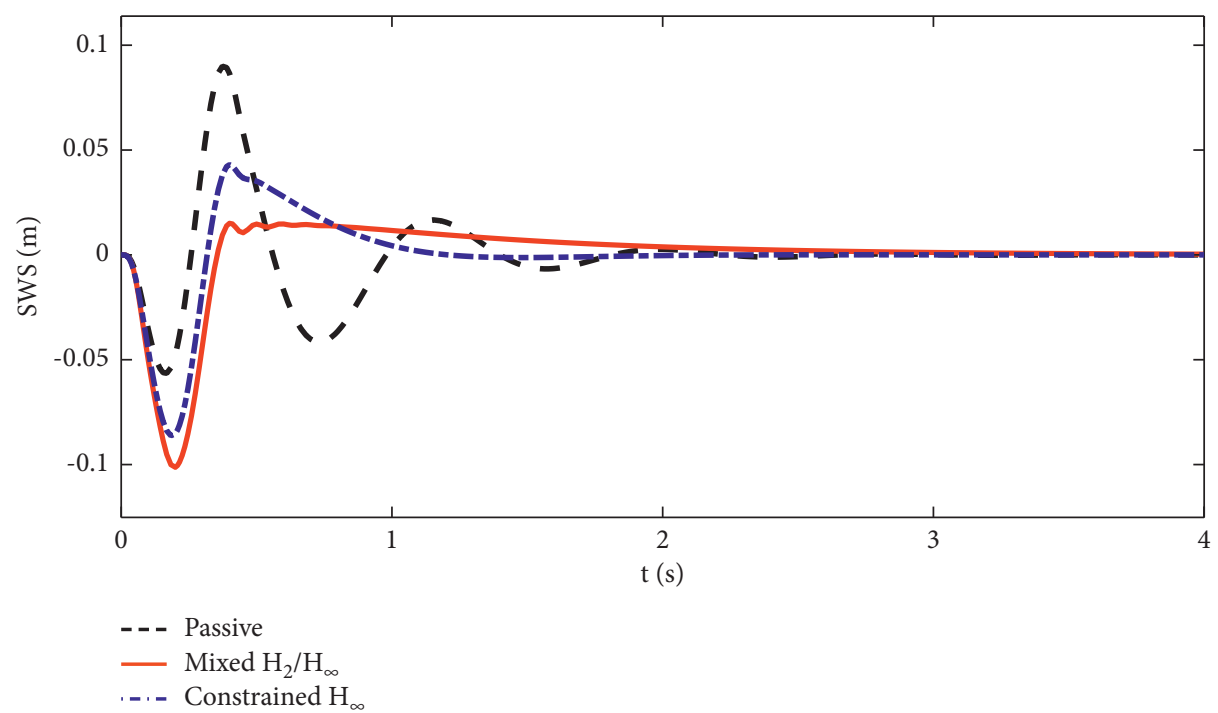

FIGURE 16: Bump working space responses of suspension with parameter variation.

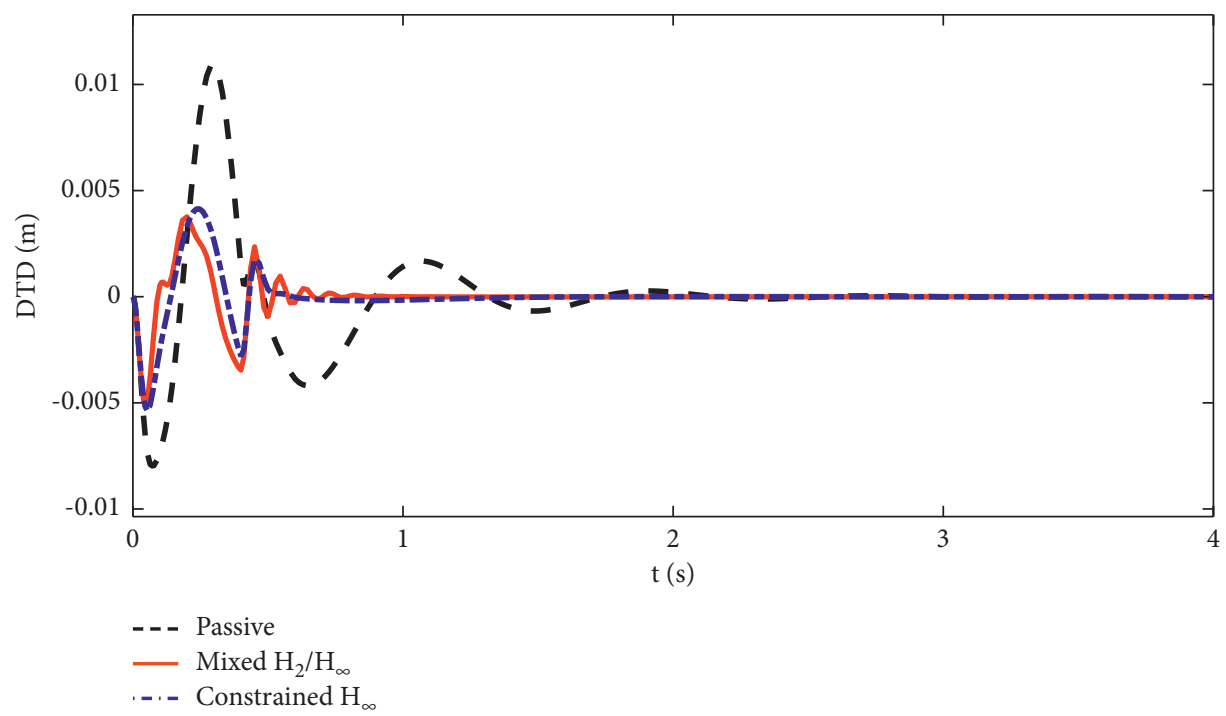

FIgURE 17: Bump dynamic tire displacement responses of suspension with parameter variation. 


\section{Conclusions}

In this paper, a mixed $\mathrm{H}_{2} / \mathrm{H}_{\mathrm{O}}$-based robust guaranteed cost controller for the IWMD-EV active suspension system considering performance requirements and parameter variations is proposed. In the design process, the uncertain quarter-vehicle active suspension model is established; we regard the vertical body acceleration as the $H_{2}$ performance index and set other requirements output as the $H_{\infty}$ performance index. Then, the proposed controller is designed using with Lyapunov stability theory. The proposed controller is simulated and compared with the constrained robust $H_{\infty}$ controller. The results show that the proposed controller has good ride comfort and handling stability performance. In the future, we will further research and compare the effects of different advanced control methods for the active suspension system of IWMD-EV. In addition, we will expand the application of the proposed control method in other vehicle control fields, such as vehicle lateral dynamics and the active steering system.

\section{Data Availability}

The data used to support the findings of this study are included within the paper.

\section{Conflicts of Interest}

The authors declare that there are no conflicts of interest regarding the publication of this paper.

\section{Acknowledgments}

This work was supported by the National Science Foundation of China (51905329), Foundation of State Key Laboratory of Automotive Simulation and Control (20181112).

\section{References}

[1] X. Jin, Z. Yu, G. Yin, and J. Wang, "Improving vehicle handling stability based on combined AFS and DYC system via robust Takagi-Sugeno fuzzy control," IEEE Transactions on Intelligent Transportation Systems, vol. 19, no. 8, pp. 2696-2707, 2017.

[2] A. Goodarzi and E. Esmailzadeh, "Design of a VDC system for all-wheel independent drive vehicles," IEEE, vol. 12, no. 6, pp. 632-639, 2007.

[3] Y. Y. Luo and D. D. Tan, "Study on the dynamics of the inwheel motor system," IEEE Transactions on Vehicular Technology, vol. 61, no. 8, pp. 3510-3518, 2012.

[4] Y. Chen, J. K. Hedrick, and K. Guo, "A novel direct yaw moment controller for in-wheel motor electric vehicles," Vehicle System Dynamics, vol. 51, no. 6, pp. 925-942, 2013.

[5] X. Jin, G. Yin, J. Chen, and N. Chen, "Robust guaranteed cost state-delayed control of yaw stability for four-wheelindependent-drive electric vehicles with active front steering system," International Journal of Vehicle Design, vol. 69, no. 1-4, pp. 304-323, 2015.

[6] B. Zheng and S. Anwar, "Yaw stability control of a steer-bywire equipped vehicle via active front wheel steering," Mechatronics, vol. 19, no. 6, pp. 799-804, 2009.
[7] C. Poussot-Vassal, O. Sename, L. Dugard, and S. M. Savaresi, "Vehicle dynamic stability improvements through gainscheduled steering and braking control," Vehicle System Dynamics, vol. 49, no. 10, pp. 1597-1621, 2011.

[8] V. Ivanov, D. Savitski, and B. Shyrokau, "A survey of traction control and antilock braking systems of full electric vehicles with individually controlled electric motors," IEEE Transactions on Vehicular Technology, vol. 64, no. 9, pp. 3878-3896, 2014.

[9] X. Jin, G. Yin, X. Zeng, and J. Chen, "Robust gain-scheduled output feedback yaw stability control for in-wheel-motordriven electric vehicles with external yaw-moment," Journal of the Franklin Institute, vol. 355, no. 18, pp. 9271-9297, 2018.

[10] "C. Bridgestone, Bridgestone Dynamic-Damping In-Wheel Motor Drive System, http://enginuitysystems.com/files/InWheel_Motor.pdf, 2017.

[11] A. Kulkarni, S. A. Ranjha, and A. Kapoor, "A quarter-car suspension model for dynamic evaluations of an in-wheel electric vehicle," Proceedings of the Institution of Mechanical Engineers - Part D: Journal of Automobile Engineering, vol. 232, no. 9, pp. 1139-1148, 2018.

[12] F. Yang, L. Zhao, Y. Yu, and C. Zhou, "Analytical description of ride comfort and optimal damping of cushion-suspension for wheel-drive electric vehicles," International Journal of Automotive Technology, vol. 18, no. 6, pp. 1121-1129, 2017.

[13] W. Wang, M. Niu, and Y. Song, "Integrated vibration control of in-wheel motor-suspensions coupling system via dynamics parameter optimization," Shock and Vibration, vol. 2019, Article ID 3702919, 14 pages, 2019.

[14] Y.-J. Liu and H. Chen, "Adaptive sliding mode control for uncertain active suspension systems with prescribed performance," IEEE Transactions on Systems, Man, and Cybernetics: Systems, vol. 51, no. 10, pp. 6414-6422, 2021.

[15] J. Na, Y. Huang, X. Wu, S. Su, and G. Li, “Adaptive finite-time fuzzy control of nonlinear active suspension systems with input delay," IEEE Transactions on Cybernetics, vol. 50, no. 6 , pp. 2639-2650, 2019.

[16] H. Li, J. Yu, C. Hilton, and H. Liu, "Adaptive sliding-mode control for nonlinear active suspension vehicle systems using T-S fuzzy approach," IEEE Transactions on Industrial Electronics, vol. 60, no. 8, pp. 3328-3338, 2012.

[17] H. D. Choi, C. K. Ahn, M. T. Lim, and M. K. Song, "Dynamic output-feedback $\mathrm{H} \infty$ control for active half-vehicle suspension systems with time-varying input delay," International Journal of Control, Automation and Systems, vol. 14, no. 1, pp. 59-68, 2016.

[18] S.-B. Choi and S.-S. Han, "Ho control of electrorheological suspension system subjected to parameter uncertainties," Mechatronics, vol. 13, no. 7, pp. 639-657, 2003.

[19] P. Li, J. Lam, and K. C. Cheung, "Multi-objective control for active vehicle suspension with wheelbase preview," Journal of Sound and Vibration, vol. 333, no. 21, pp. 5269-5282, 2014.

[20] P. P. Khargonakar, I. R. Petersen, and K. Zhou, "Robust stabilization of uncertain linear systems: quadratic stability and Ho control theory," IEEE Transactions on Automatic Control, vol. 35, no. 5, pp. 356-361, 1990.

[21] I. R. Petersen, B. D. O. Anderson, and E. A. Jonckheere, “A first principles solution to the non-singularHo control problem," International Journal of Robust and Nonlinear Control, vol. 1, no. 3, pp. 171-185, 1991.

[22] K. Jbilou, A. Messaoudi, and K. Tabaâ, "Some Schur complement identities and applications to matrix extrapolation methods," Linear Algebra and Its Applications, vol. 392, pp. 195-210, 2014. 
[23] H. Liang, G. Liu, H. Zhang, and T. Huang, "Neural-networkbased event-triggered adaptive control of nonaffine nonlinear multiagent systems with dynamic uncertainties," IEEE Transactions on Neural Networks and Learning Systems, vol. 32, no. 5, pp. 2239-2250, 2021.

[24] L. Liu, Y. Liu, A. Chen, S. Tong, and C. P. Chen, "Integral barrier Lyapunov function-based adaptive control for switched nonlinear systems," Science China Information Sciences, vol. 63, no. 3, pp. 1-14, 2020.

[25] H. Liang, X. Guo, Y. Pan, and T. Huang, "Event-triggered fuzzy bipartite tracking control for network systems based on distributed reduced-order observers," IEEE Transactions on Fuzzy Systems, vol. 29, no. 6, pp. 1601-1614, 2021.

[26] I. Ahmad, X. Ge, and Q.-L. Han, "Decentralized dynamic event-triggered communication and active suspension control of in-wheel motor driven electric vehicles with dynamic damping," IEEE/CAA Journal of Automatica Sinica, vol. 8, no. 5, pp. 971-986, 2021.

[27] X. Ge, I. Ahmad, Q.-L. Han, J. Wang, and X.-M. Zhang, "Dynamic event-triggered scheduling and control for vehicle active suspension over controller area network," Mechanical Systems and Signal Processing, vol. 152, Article ID 107481, 2021.

[28] X. Jin, J. Wang, Z. Yan, L. Xu, G. Yin, and N. Chen, "Robust vibration control for active suspension system of in-wheelmotor-driven electric vehicle via $\mu$-synthesis methodology," ASME Transactions Journal of Dynamic Systems, Measurement, and Control, 2021.

[29] X. Jin, J. Wang, S. Sun, S. Li, J. Yang, and Z. Yan, “Design of constrained robust controller for active suspension of inwheel-drive electric vehicles," Mathematics, vol. 9, no. 3, 2021. 